\title{
sciendo
}

\section{Business excellence models in higher education - innovative solutions for management performance}

\author{
Alina Mihaela DIMA \\ The Bucharest University of Economic Studies, Bucharest, Romania \\ alinamihaeladima@yahoo.com \\ Roxana CLODNIT⿱CHI \\ The Bucharest University of Economic Studies, Bucharest, Romania \\ Laura ISTUDOR \\ The Bucharest University of Economic Studies, Bucharest, Romania \\ Iulia LUCHIAN \\ The Bucharest University of Economic Studies, Bucharest, Romania
}

\begin{abstract}
The present challenging environment determines organizations to differentiate themselves from their competitors finding creative solutions. Business Excellence Models (BEMs) is the appropriate instrument for organizations to create authentic competitive advantages. In dynamic and changing environments characterized by technological changes, a sustainable advantage requires strong dynamic capabilities and integrated elements of BEMS. A comparative analysis of BEMS evolution presented in the paper reflects the challenges and opportunities for further improvement in organizations. Excellence models have been used successfully also in business education. Business education reflects the added value to sound economic development, balancing social and economic interest (Emiliani, 2004). In general, it refers to competitive and motivated academic staff, quality of teaching and learning activities, leadership and management commitment, sustainability of university-business relationship, internationalization strategy and comprehensive curriculum adapted to business environment. There are a lot of environmental forces in different national environments that are placing the excellence dimension on higher education agenda. At the same time, limitations of BEMs models and the nature of higher education institutions put a lot of challenges on leadership and management of these organizations. The objective of the paper is to present and analyse the application of excellence models in higher education institutions and identify creative solutions for management performance.
\end{abstract}

Keywords: business excellence, higher education, business excellence model, creativity.

\section{Introduction}

In the context of the creative economy, a concept coined by John Howkins (2001), since innovation in several industries, especially the IT industry, brought new ways of living and doing business, it is of great importance to acknowledge their impact on people's lives and to incorporate these new techniques into the business models of companies. Therefore, companies from different sectors of the economy can make use of one another's knowledge with the purpose of developing new ways of doing business. 
Improving processes and developing new techniques is an accelerator of productivity in every industry (Suciu, 2008).

Several authors described the creative industries with the help of the fundamental domains they include, among which Hesmondhalgh (2002) and Howkins (2001) mention advertising, video games, editing, radio, film. Creative products and services are characterized by the intangible factor and might take various shapes, from theories and hypotheses to designs and materials, with the possibility of being developed in any sector of the economy (Suciu, 2004).

As we are now witnessing the fourth industrial revolution, which brings technology breakthroughs in several fields such as artificial intelligence, biotechnology, robotics, the challenge of adapting to these changes arises for organizations all over the world (Schwab, 2016). While these changes in the way of doing business are intended to make organizations more efficient and perform their activities in ways that can lead to the regeneration of natural resources and the environment, the question of whether they can all adapt must also be addressed.

At a smaller scale, innovation in business can appear from the improvement of processes and development of new techniques that can ensure competitive advantage in nowadays highly competitive market. It is of utmost importance for businesses in all industries to improve their business models, as the spread of access to technology will bring into the market new providers of products and services.

The customer needs are also constantly changing, forcing businesses to constantly deliver new products to the market in order to ensure survival, while keeping a value-oriented approach.

The quest of business innovation attracted the development of business excellence models, as tools that provide guidelines in identifying problems and developing solutions on the path to achieving business excellence for organizations of all sizes and belonging both to the private and public sectors. The existing business excellence models, among which we can mention the European Foundation for Quality Management, the Malcolm Baldrige Award, the Australian Business Excellence Framework, the Deming Prize, focus on areas such as customer focus, management of processes, employee development, effective communication, obtaining quality results. Of these, the European Foundation for Quality Management is the most popular excellence model used in Europe, as the majority of European organisations use it for selfperformance evaluation.

\section{Excellence Business models applied to higher education}

The concept can be successfully applied to the higher education institutions, observing the needs of the current society and taking measures to deliver high quality education. The expectations of nowadays society are very high in regard to the contribution of universities to the shaping of new generations of workers and leaders around the world. Excellence is expected from higher education institutions on various levels like research and innovation, teaching, leadership.

However, the general perception is that the vast majority of higher education institutions are not effective in meeting the needs of communities and businesses by preparing their students for their future activity in the labour market. As Ghinea et al. (2017) argue, the concept of excellence is perceived in different ways by higher education institutions in relation with their organizational culture and socio-economic and political conditions. In order to achieve excellence, these institutions should address all aspects 
of the academic life, including the management, teaching, learning and the research community.

As Anninos and Chytiris (2012) claim, education is a sector where excellence is perceived through the quality of the teaching staff and infrastructure, the connexion between the university and the business environment, partnerships with foreign higher education institutions and the constant adjustment of the curricula in order to accommodate the fast changes taking place in the business environment. By constantly updating the curricula, universities are able to provide their students with knowledge and abilities required for their future work positions in the market.

Collaboration with the business environment is crucial for higher education institutions, as it ensures higher employability for their graduates, by matching the graduates skills with the needs of employers.

Communication is an important element for the achievement of excellence in higher education, both inside the organisation, as well as with the students enrolled in education programs. Since the appearance of alternate communication platforms such as the ones belonging to social media, there has been a shift in the way universities communicate with their students, in the sense that communication has been digitalized, and announcements, as well as different activities can be done online, avoiding confusion, misinformation and bureaucracy.

By increasing communication with their students, it becomes easier for higher education institutions to inform the latter of future events, achievements and other such topics, thus displaying a more transparent way of operating and creating online students' engagement. Showing transparency towards students is similar to businesses showing transparency to their customers, which is a positive action for the brand image.

The existing business excellence models offer guidance in the process of achieving performance excellence for organizations belonging to different sectors, identifying issues and stimulating solutions. However, some of them can be more easily adapted to the business environment and more difficult to transfer to higher education institutions.

In order to achieve excellence in higher education, it is crucial to bring improvements to the student experience, by successfully identifying and even anticipating the needs of the students.

Excellence in higher education has been seen by Hides et al. (2004) as a sum of several achievements among which attaining the mission and vision of the organisation, becoming a best practice example for others, reaching and exceeding internal targets, achieving stakeholder satisfaction by using all resources optimally.

Contrary to the implementation of excellence models leading to successful stories in organisations, there are some researchers which do not support their adaptation to higher education. According to Becket and Brooks (2008), industrial models do not properly address the learning experience of students due to their diversity and inability to compare them with customers from different sectors of the economy. Therefore, they argue that despite the benefits of total quality management, higher education should make use of different approaches for measuring quality and claim that adapting business excellence models to educational institutions is difficult to accomplish. Cruickshank (2003) and later also Arjomandi (2009) stress that such models have a higher applicability is in administrative areas but meet their limits in critical areas like the quality of research.

Srikanthan and Dalrymple (2004) underline the higher education institutions' bureaucratic structures and the academics' traditional autonomous role as opposed to the predominant team-based approach supported by QM. 
Among the difficulties in adapting business excellence models to higher education, Vroeijenstijn (2001) shows the fact that it is difficult to establish what product or service is provided, given the different nature of education and that the client is also rather difficult to identify. The author also mentions the structure of universities, which are not designed as hierarchical organisation and the fact that quality is very difficult to asses in the given environment of higher education institutions, where the actions of teaching and learning bear a personal component.

From the selected business excellence models, all of them put an emphasis on process improvement and analysis, while the European Foundation for Quality Management focuses on customer satisfaction, the Deming Prize focuses on the improvement of processes, the Malcolm Baldrige Award pays particular attention to business results and the Australian models highlight effective communication within the organization, strategy improvements and qualitative results. (Vokurka, 2000)

As the widely used business excellence model in Europe, the European Foundation for Quality Management has the role to support organisations in achieving customer and people satisfaction, which in higher education refer to student and teaching staff satisfaction. These are expected to happen while also attaining business results and society results, which for the higher education system refer to obtaining excellent results in all areas of activity, while managing to exceed the expectations of stakeholders within society.

The American business excellence model, Malcolm Baldrige Award emphasizes customer satisfaction and the importance of process management and improvement, focusing on business results and strong leadership, while not forgetting to mention all key areas such as the workforce and the quality of the products or services provided. In the higher education organisations, processes tend to be lengthy and affected by bureaucracy, and the activities performed have a different nature than the one of business entities. However, strong leadership and quality of teaching, as well as research activities can lead the path to excellent results.

The Japanese Deming Prize focuses on ten criteria, among which quality control, human resources development and future planning. The focus on quality brings improvements to the student experience in higher education institutions.

The Australian Business Excellence Framework and Australian Business Models for Higher Education bring forward similar areas of improvement, such as strategy in the case of ABEF and quality control in the case of the Australian Business Models for Higher Education.

\section{Analysis of excellence models impact on university performance}

The literature on the topic of BEMs is comprised of various theories, each of them putting focus on a specific factor.

\section{EFQM-European Foundation for Quality Management}

In Europe, a popular BEM is the European Foundation for Quality Management (EQFM), an excellence model which is based on eight fundamental concepts: results orientation; customer focus; leadership and constancy of purpose; management by processes and facts; people development and involvement; continuous learning; innovation and improvement; and partnership development and public responsibility (Dahlagaard, Park, 2007).

However, the main focus is on leadership management that is further oriented to two main directions, performance management inside of the higher education institutions and the identification of the correct key performance results for its various 
students. Hence, it identifies and discusses the critical success factors for the university (Hohan, Olaru, Pirnea, 2015). It promotes the use of a standard management model capable of bringing the organization to excellence level and a standard evaluation process that could be applied to all types of organizations, regardless of sector, size, structure or maturity (Campatelli, 2011).

The advantages to introduce this model could be the understanding and anticipation of the students' expectations (Hohan, Olaru, Pirnea, 2015) as well as impress a visionary and inspirational leadership style among the employees (Hohan, Olaru, Pirnea, 2011). However, the EQFM model is a very time consuming process that requires the allocation of a lot of resources (IT Governance Institute, 2007).

Its roots come from the implementation at companies' level where it represents also a model for business excellence. The main areas of focus consist in adjusting businesses and security objectives, bring efforts together to create a security performance and share the best practice and knowledge. This model focuses on discovering the strengths and shortcomings in regards to best practices and the vision and mission of the companies. It includes components such as principles based on a set of European values which has their roots in the European Convention on Human Rights (Hohan, Olaru, Pirnea, 2015).

\section{Malcolm Baldrige Model}

In the United States of America, a popular model is the Malcom Baldrige, established in 1987 (Vora, 2013) that mainly encourages young people to pursue an entrepreneurial approach and to develop their leadership skills. At company level, the Baldrige Model is based on a framework of performance excellence which can be used by organisations to improve performance. This includes 7 categories of criteria: leadership; strategic planning; customer and market focus; measurement, analysis, and knowledge management; human resource focus; process management; and results (Brookes, Becket, 2007).

Hence, the main advantage of implementation of Malcolm Baldrige model is the higher level of student engagement in the learning process. The proof of this state of being is the feedback to the instructors that is more abundant and of better quality (RochaLona, Garza-Reyez, Kumar, 2015). Moreover, some other benefits may be the immediate and long standing results (Arif\&Smiley, 2004). In this way, the model increases the level of student engagement and fosters a better relationship between the professors and the students (Rocha-Lona, Garza-Reyez, Kumar, 2015). On the other hand, the drawbacks of this model could be the complexity itself of the model and the high implementation costs (Rocha-Lona, Garza-Reyez, Kumar, 2013).

\section{Australian Business Excellence Framework}

In terms of implementation of ABEF model in the business world, there, it outlines an integrated leadership and management processes which describes the essential elements at different levels of performance. Among its main goals there are improvement of strategy and planning, information and knowledge, product quality and service delivery (Brown, 2012).

The ABEF model proposes to students an entrepreneurial approach with a focus on the development of leadership skills and the attempt to achieve excellence on a daily basis (Brown, 2012). This model's main drawback consists of the high implementation costs (Eriksson, Garvare, 2005). The ABEF, like other frameworks, are not prescriptive 
about managing organizations, rather they serve as a guide for organizational strategy and improvement (Brown, 2013).

\section{Australian Business Models for higher education}

The Australian Business Models for Higher Education are represented in a variety of ways and forms among them: „bricks and mortar” (physical), „clicks and mortar” (digital) and hybrid versions. This emphasizes the relationships between people, products and services, market condition and its value (Bokor, 2011). This model adds a high value on the quality of the students' process of learning and developing themselves, teaching them to stay focused long-term and provide the necessary outcome in order to have excellent results (Osterwalder, Pigneur, Tucci, 2005). Another advantahe includes the reputation of the teaching and research staff and the quality of their networks and collaborative relationships (Xuemei, 2014).

The main goal of the Australian Business Models was to accommodate the vibrant demand for places from international students, include among them adjustments to their costs and revenue components (Bokor, 2011).

\section{Deming Prize}

Recognition of the value of self-assessment became public knowledge when the Deming Prize was launched in Japan in 1951 (Jackson, 1999). The Deminig Prize BEM outlines the principles of continuous improvement as it provides a roadmap for excellence and inspires through doing. The main advantage of this model is that its implementation in the high education institutions ensures a higher focus on quality, not on the quantity of the students work and it makes them think more on the outcome of their effort and to stay focused on long-term (Talwar, 2010). However, literature notes that the productivity of the institution may slightly decrease until the model is implemented and proves to be up and running (Talwar, 2009).

\section{Discussion: Implementing EFQM-European Foundation for Quality Management in Higher Education Institutions}

Literature shows us that several universities have begun to use quality management models, including the excellence model developed by EFQM (Sadeh and Garkaz, 2015). Furthermore, Zink and Schmidt (1995) demonstrate that the nine criteria may be applied to universities. They argue that they can be operationalized in order to fit the university context. Also they conclude that the implementation of such a system can ultimately lead to cost savings for higher education institutions.

\section{Benefits}

The benefits of the implementation of such a model quite many. Starting with EFQM as a tool for self-assessment, the implementation of such a system allows the creation of structures for continuous improvement. Tóvölgyi (2009) and Tari (2010) show that EFQM-systems in higher education not only help identifying strengths and weaknesses but also sustain the development and implementation of improvement strategies. Since an important amount of employees from several departments - administrative and didactic - are involved in the process analysis and the implementation of change within an EFQM based system, you also gain a higher commitment and identification of the employees with the institution and a higher involvement for quality improvement. In the long run, this consciences leads to a shift in the institutions set of values and culture. The higher education institution well have now a quality continuous improvement culture. 
Tóvölgyi (2009) also describes the implementation of a EFQM-based quality management system as a tool for promoting sustained and objective decision-making, based on facts, indexes, indicators and not subjectivity. Within the implementation of an EFQM-system, not only helps improve administrative processes but can, according to Sadeh and Garkaz (2015) also improve the quality of educational services which can raise the satisfaction of students.

We should als not neglect the spill-over effect. Tóvölgyi (2009) and Tari (2010) show that an increased knowledge of professors with regard to quality-related issues, given by implementation of EQFM in higher education institutions, can lead to a higher future employers' and employees' awareness regarding the importance of quality, allowing higher efficacy and efficiency of the students' future companies.

Last but not less important, by implementing a EQFM-based quality management system, higher education institutions can participate to the contest for the EQFM-Award and gain herewith important marketing capital. Zink and Schmidt (1995) underline that the winners are benefit from extensive media coverage.

\section{Difficulties}

Higher education institutions meet several difficulties when implementing an EFQM model. Probably the most important difficulty to mention is the limited resources at the disposal of most higher education institutions. Especially in the case of publicly founded universities, so Tari (2010).

Not only the financial resources are scarce, but also the necessary human capital. Since the implementation of a QM is time intensive and also requires skills, universities face their administrative limits whenever they want to approach a change in the management approach.

The implementation of change requires next to the beginning enthusiasm a long term commitment. In most higher education institutions as well the management elected by vote as also the staff, civil servants - with most secure jobs, lack the motivation and the discipline to consciously implement a EQFM-system.

The implementation of any QM-system also requires knowledge in total quality management (TQM) as well as some experience in the field. Since TQM is less common in public institutions, there are seldom available experts to employ in higher education institutions. Next to QM-knowledge, several employees should be proficient in process management. Campatelli (2011) also stresses that public administration processes are very complex as they are and that is hard to reconcile them with TQM.

\section{Recommendations}

Considering the above, the successful implementation of an quality management system based on EFQM requires first of all experienced, motivated and committed management employees, ready to take on the leadership role and consequently communicating and enabling the employees to perform the change. The know-how of management and staff can permanently be improved by specific training and development measures, aimed at creating knowledgeable environment.

Last but not least, follow-up and objective reporting is critical to develop a culture of continuous improvement. 


\section{References}

Anninos, L.N. \& Chytiris, L. (2011). Searching for excellence in business education. Journal of Management Development, 30(9), 882-892.

Arjomandi, M., Kestell, C. and Grimshaw, P. (2009). An EFQM excellence model for higher education quality assessment, Proceedings of the 20th AAEE Australasian Association for Engineering Education Conference, pp. 1015-1020.

Beket, N., \& Brooks, M. (2008). Quality management practice in higher education - what quality are we actuallyenhancing? Journal of Hospitality, Leisure, Sport \& Tourism Education, 7(1), 40-54.

Arif, M. and Smiley, F. (2004) Baldridge theory into practice: a working model. International Journal of Educational management, 18(5), 324 - 328.

Brookes, M. and Becket, N. (2007) Quality Management in Higher Education: A Review of International Issues and Practice. International Journal of Quality and Standards, $1,1-37$.

Brown A (2012). Managing challenges in sustaining business excellence, pp.466-473.

Brown, A. (2013),"Managing challenges in sustaining business excellence", International Journal of Quality \& Reliability Management, Vol. 30 Iss 4 pp. 461 - 475

Campatelli, G., Citti, P., Meneghin, A. (2011). Development of a simplified approach based on the EFQM model and Six Sigma for the implementation of TQM principles in a university administration. Total Quality Management and Business Excellence, 22(7), 691-704

Cruickshank, M. (2003). Total quality management in the higher education sector: a literature review from an international and Australian perspective, TQM and Business Excellence, Vol. 14No. 10, pp. 1159-1167.

Dahlgaard-Park, S.M., Dahlgaard,J., (2007),"Excellence - 25 years evolution", Journal of Management History, Vol. 13 Iss 4 pp. 371 - 393

Eriksson, H. and Garvare, R. (2005). Organisational performance improvement through quality award process participation, International Journal of Quality \& Reliability Management, Vol. 22 No. 9, pp. 894-912

Ghinea, V.M., Dima, A.M. \& Hadad, S. (2017). Excellence Model for Sustainable Convergence in the EU Higher Education. Amfiteatru Economic, 19 (Special No. 11), 1107-1122.

Hesmondhalgh, D. (2002). The Cultural Industries. SAGE Publications Ltd.

Hides, M.T., Davis, J., \& Jackson, S. (2004). Implementation of EFQM Excellence Model selfassessment in the UK higher education sector - lessons learned from other sectors. The TQM Magazine, 194-201.

Howkins, J. (2001). The Creative Economy: How People Make Money From Ideas. United Kingdom: Penguin UK.Hohan, A.I, Olaru, M., Pirnea, IC (2015). Assessment and continuous improvement of information security based on TQM and business excellence principles, Emerging Markets Queries in Finance and Business, pp. 356359.

Hohan, A.I, Olaru, M., Pirnea, IC(2011). Case study regarding the implementation of an integrated risk management system in local public administration, Quality access to success Journal, II, pp.246-251.

IT Governance Institute (2007) CoBIT 4.1, Framework, Control Objectives, Management Guidelines, Maturity Models, pp 175-176. 
Jackson, S. (1999),"Achieving a culture of continuous improvement by adopting the principles of self-assessment and business excellence", International Journal of Health Care Quality Assurance, Vol. 12 Iss 2 pp. 59 - 64

Osterwalder, A., Pigneur, Y. and Tucci, C. (2005). Clarifying business models: origin, present and future of the concept, Communications of the Association for Information Systems, Vol. 15 Article 1, pp. 1-43.

Rocha-Lona L., Garza-Reyez J.A., Kumar V (2015). Corporate Sustainability and Business Excellence, pp. 3-6

Rocha-Lona, L., J.A. Garza-Reyes, and V. Kumar (2013). Building quality management systems; selecting the right methods and tools. Reference and Research Book News, pp.28.

Sadeh, E. and Garkaz, M. (2015). Explaining the mediating role of service quality between quality management enablers and students' satisfaction in higher education institutes: the perception of managers, Total Quality Management \& Business Excellence, Vol. 26 , pp. 1335-1356.

Schwab, K. (2016). The Fourth Industrial Revolution. New York: Random House USA Inc. Srikanthan, G. and Dalrymple, J. (2002). Developing a holistic model for quality in higher education", Quality in Higher Education, Vol. 8 No. 3, pp. 216-224.

Srikanthan, G. and Dalrymple, J. (2004). A synthesis of a quality management model for education in universities", International Journal of Educational Management, Vol. 18 No. 4, pp. 266-279.

Suciu, M. C. (2004). Economia si societatea bazata pe cunoastere/Economy and knowledge-based society. Vol II, Ch. 19. Bucharest, RO: Editura ASE Bucuresti.

Suciu, M. C. (2008). The Creative Economy. Vol. 15, Issue 1. Bucharest, R0: Lex et Scientia. Talwar B. (2010). Business Excellence Models and the path ahead, pp. 22-25.

Talwar, B. (2009). Comparative study of core values of excellence models vis-a'-vis human values", Measuring Business Excellence, Vol. 13 No. 4, pp. 34-46.

Tarí, J.J. (2010). Self-assessment processes: the importance of follow-up for success, Quality Assurance in Education, Vol. 18 No. 1, pp. 19-33.

Tolofari, S. (2005). New public management and education, Policy Futures in Education, Vol. 3No. 1, pp. 75-89.

Vokurka,R.J. Stading, G.L. \& Brazeal, J. (2000). A comparative analysis of national and regional quality awards. Quality Progress, 33(8), 41-49.

Vora , M. K. (2013),"Business excellence through sustainable change management", The TQM Journal, Vol. 25 Iss 6 pp. 625 - 640 .

Vroeijenstijn A.I. (2001). Towards a Quality Model for Higher Education. INQAAHE-2001 Conference on Quality, Standards and Recognition. Bangalore, March 2001.Xuemei T.B.M. (2014). Business models for higher education: an Australian perspective, Journal of Management Development, Vol. 33, pp. 932 - 948.

Zink, K.J. and Schmidt, A. (1995). Measuring universities against the European quality award criteria, Total Quality Management, Vol. 6 No. 5, pp. 547-562. 